\title{
Evaluating the Program of Parents Behavioral Training and Cognitive Training Effect- the Child's Behavior on Decreasing the Symptoms of Deficit Attention Disorder/Hyperactivity
}

\author{
Ali Jafari Nodoshan ${ }^{1}$, Fariborz Dortaj ${ }^{2}$, Hamid Alizadeh ${ }^{2}$, Valiollah Farzad ${ }^{3} \&$ Tahereh Sadeqie $^{4}$ \\ ${ }^{1}$ The research-based PhD student in educational psychology, International Imam Reza (AS) University, Mashhad, \\ Iran (Paper author) \\ $2 \mathrm{PhD}$, Faculty of psychology and Educational sciences, Allameh Tabataba'i University, Hemmat \\ Expressway-West, Dehkadeh Sq., Postalcode: 1489684511, Tehran, Iran \\ ${ }^{3} \mathrm{PhD}$, Faculty of Psychology \& Educational sciences, Kharazmi University, Tehran, Iran \\ ${ }^{4} \mathrm{PhD}$, Child and Adolescent Psychiatrist, Assistant Professor of Psychiatry, Medicine Faculty, University of \\ Sadoughi, Yazd, Iran \\ Correspondence: Ali Jafari Nodoshan, the research-based PhD student in educational psychology, International \\ Imam Reza (AS) University, Mashhad, Iran. E-mail: esfehani.mohamad3@gmail.com
}

Received: September 21, 2016

Accepted: October 8, $2016 \quad$ Online Published: October 28, 2016

doi:10.5539/mas.v11n2p39

URL: http://dx.doi.org/10.5539/mas.v11n2p39

\begin{abstract}
Deficit attention disorder/hyperactivity is one of the most popular psychiatric disorders in childhood. The aim of this study was evaluating and comparing the program of parent's behavioral training and cognitive training effect- The child's behavior on decreasing the symptoms of deficit attention disorder/hyperactivity of 8 to 12 years old children in Yazd city.

This study is quasi-experimental and the research plan is multi-group pre-test - post-test with control group. The research sample consisted of 47 persons. Thus, the behavioral parent training group was replaced 17 persons, cognitive behavioral experimental group 15 persons and 15 persons control group.

Data showed that parent's behavioral training has effect on decreasing the symptoms of deficit attention disorder/hyperactivity of 8 to 12 years olds children but child's behavior cognitive training doesn't have effect on decreasing the symptoms of deficit attention disorder/hyperactivity.

According to the research result which shows the efficiency of parent's behavioral training method than child's behavior cognitive training on decreasing the symptoms of deficit attention disorder/hyperactivity. It seems that using this training method is effective and can be suggested for reducing the symptoms of this disorder.
\end{abstract}

Keywords: deficit attention disorder/hyperactivity, parent's behavioral training, behavioral cognitive training

\section{Introduction}

Deficit attention disorder/hyperactivity is one of the most popular psychiatric disorders in childhood (Blasco, Fontsila \& colleagues, 2015) which is estimated that likely $10 \%$ of children are include the growth neurological disorders (Esmit \& colleagues, 2016; Perz, 2015), in the world wide boys compared to girls have this disorder three to one (Mishra \& colleagues, 2016) and its prevalence is three to one in boys than girls and this ratio is 5: 1 to 9: 1 in the referred to clinic samples (Ascolgi and colleagues, 2013) the findings of the study show that genetic and environmental factors play an important role in the formation of this disorder (Tipper \& Cooper, 2016) and it is diagnosed before age 7 (Sarraf \& colleagues, 2015) and often continues into adulthood (Petsic \& colleagues).

The main symptoms of this disorder include attention deficit disorder, hyperactivity and impulsivity (Alizadeh \& colleagues, 2013). Parents of these children complain that they don't have accuracy in their activities and usually they don't follow their work to end (Berkeley, 1998). Also children who are mostly the component of the under scale impulsive have many motions and activities and they seek the environment non-targeted in situations that are expected to remain calm (Kouchak zade \& colleagues, 2015) and they accost with serious problems in academic, social and cognitive performances (parted, 2013; Hakim \& colleagues, 2015; Aliakbari \& colleagues, 
2015).

Parents of these children have to loss all their energy by controlling their children (Malik Pur \& colleagues, 2013) Some studies show that the mothers of these children feel greater mental stress than parents of normal children (Kordestani, 2014; Zareie \& colleagues, 2014; Abdol karimi \& colleagues, 2011) and their children are criticized due to the frequent carelessness, impulsivity and excessive activities, and a chronic unhealthy relationship is formed between them (Jafari \& colleagues, 2011) that its result is being affected the self-concept (Huck, 2011) and interactions of these children with parents (Amiri \& colleagues, 2013).

According to what was said, it is explainable the necessity of evaluating and comparing the different effective educational-treatment methods. For years, it have been tried in various studies to determine the best educational and treatment methods but there isn't any unique method which is considered the best treatment method, yet. Now the drug treatment is the first line of therapy for this disorder and behavioral training such parent's behavioral training and behavioral management are considered as complementary therapies (Bahieet, 2011). This training method (parents training) is used as a suitable method, multifaceted and innovative for managing the undesirable and harasser behaviors of these children (Alizadeh, 2012).

In Iran some concluded researches show that parent's behavioral training is effective on decreasing the symptoms of deficit attention disorder/hyperactivity. For example, Meftaq \& colleagues showed in the research that parent's behavioral training is effective and efficient on decreasing the impulsive intensity and general intensity of symptoms. In a separate research, Bahmani and alizaded (2011) concluded from their study that parent's management training program is effective on reducing symptoms of attention deficit disorder/hyperactivity and improving their parenting method.

Also Narimani and colleagues (2014) showed in a study that parent's management training is effective on reducing the symptoms of impulsivity and less-attention of children with attention deficit disorder/ hyperactivity. Abedi and colleagues (2012), Weysani and colleagues (2015) and Khodabakhshi and colleagues (2015) showed the effectiveness of positive parenting program on reducing symptoms of attention deficit disorder/hyperactivity, in separate studies.

Some another researches show that behavioral techniques is serious in decreasing the symptoms of this doubtful disorder (American Psychiatric Association, 2001; quoted by Page \& colleagues, 2003). Alizade (2012) concludes in a research that however parents training program has significant effect on reducing parents stress and increasing the parenting method (authoritarian style) but it has not been effective on decreasing symptoms of attention deficit disorder/hyperactivity of their children.

Another intervention method that has been used in reducing the symptoms of this disorder is cognitive behavioral training. Cognitive behavioral interventions are based on this assumption that emotion and behavior are a function of cognitive. For this reason, it is possible to make changes in thinking, emotion and behavior of persons by cognitive behavioral interventions, individuals (Astlard, 2005/2010). The results have reported oppositely about the application of this type of intervention method on reducing the symptoms of attention deficit disorder / hyperactivity (Bahyat, 2011).

As an example, Meftaq and colleagues (2011) know effective both two methods on reducing the symptoms of this disorder by comparing two cognitive training methods of verbal self-training and parent's behavioral training. Soleimani and colleagues (2013) in a research know effective the cognitive training on some cognitive skills but they concludes that this raining method has not any effect on reducing clinical signs and intensity symptoms of attention deficit / hyperactivity.

Hassan abadi and colleagues (2012) compared two drug treatment and behavioral cognitive methods on reducing the symptoms of this disorder and concluded that however both two methods are effective on reducing the symptoms but behavioral cognitive method is more effective on reducing the symptoms of this disorder. Saffern and colleagues (2010 quoted by Antshel \& colleagues, 2014; Vander, 1995/1392; Ramsi \& Rastin, 1390/2005) know this method useful just for teenagers and adults with attention deficit / hyperactivity. Pelham and colleagues (1998) believe that behavioral cognitive training is not effective on reducing the symptoms of children with attention deficit / hyperactivity (Bakhshayesh, 2010) The necessity of doing further research is seen according to what said about conflicting reports about the parent's behavioral training and cognitive- training methods. Therefore, in this study it is evaluated to comparing the effectiveness of parent's behavioral training and cognitive behavioral methods on reducing the symptoms of attention deficit disorder/hyperactivity of 8 to 12 years old children. For this purpose, assumptions are presented according to research background:

- Parent's behavioral training is effective on reducing the symptoms of attention deficit disorder/ hyperactivity 
(Subgroups of mainly inattention, mainly impulsivity and combined).

- Cognitive behavioral training is effective on reducing the symptoms of attention deficit disorder/ hyperactivity (Subgroups of mainly inattention, mainly impulsivity and combined).

\section{Method}

This study is a quasi-experimental and research design, pre-test - post-test multy-group with the control group. The study population included all students whose ages 8 to 12 years that due to behavioral and academic problems had been referred to core areas of counseling and advice clinic of Imam Hossein in Yazd city .

The sample research consisted of 47 subject persons who were selected by available sampling. Subject Male and female were between the ages of 8 to 12 years old. Thus, 19 persons in the second grade, 13 persons in the third grade, 8 persons in fourth grade, and 7 persons in the fifth grade.

The mean and detour of the age was respectively, 40/9 and 18/1 in entire groups. In These three groups were 12 girls and 35 boys. In this case, students who through interviews with parents, parents' Connor's test and psychiatrists had symptoms of the disorder.

Family participated in this research with satisfaction. Experimental groups' Parents in tow levels of pre and post-intervention and control group's Parental in tow levels of pre-test and post-test answered to Diagnostic questionnaire of attention deficit Disorder / hyperactivity, according to the fourth edition of America Psychiatric Association Diagnostic and statistical Manual of Mental Disorders. To form the experimental groups and control group and also control of variables that were predicting be affective in pro-test results and is making Defaced the experimental effectiveness performance, has been used the methods of testing matched the groups according to the means of the dependent variable pre-test, symptoms of attention deficit/hyperactivity, intelligence, parental education and grade (difference of matched groups Means was not significant statistically). Thus, the behavioral training group of parent was 17 persons, cognitive behavioral experimental group of children was 15 persons and were replaced 15 persons in control group and behavioral training of parents conducted in eight 90-minute sessions over eight weeks (February \& March month of 2015) .

Table 1.

\begin{tabular}{|c|c|}
\hline Sessions & Content \\
\hline $\begin{array}{l}\text { First } \\
\text { season }\end{array}$ & $\begin{array}{l}\text { The introduction of trainer, topic of education, the overall goal of training, number of sessions, and } \\
\text { teaching the signs and symptoms of attention deficit / hyperactivity disorder }\end{array}$ \\
\hline $\begin{array}{l}\text { Second } \\
\text { season }\end{array}$ & $\begin{array}{l}\text { Free talking about parental views about the causes of children's ill-treatment. } \\
\text { (A child's psychological characteristics, (b) parent's characteristics (c) stressful family events, (d) } \\
\text { the positional consequences) }\end{array}$ \\
\hline $\begin{array}{l}\text { Third } \\
\text { season }\end{array}$ & $\begin{array}{l}\text { Establishing new desired behaviors methods (observed pattern method consistent with Bandura's } \\
\text { theory, Chain making consistent with the theory of conditioning agent, present Symmetrical for the } \\
\text { desired behavior) }\end{array}$ \\
\hline $\begin{array}{l}\text { Forth } \\
\text { season }\end{array}$ & $\begin{array}{l}\text { Methods of maintaining available desired behaviors by parents (Offering incentives pattern) and } \\
\text { parents' acquaintance with learning how to use amplifiers continuous and discontinuous } \\
\text { corresponds to the number and at different times. }\end{array}$ \\
\hline $\begin{array}{l}\text { Fifth } \\
\text { season }\end{array}$ & $\begin{array}{l}\text { Attention to desired behaviors and increase available desired behaviors methods by using positive } \\
\text { reinforcement method (principle of Prymak application and use of activities amplifier in the form of } \\
\text { focus and emotional games) and negative reinforcement to increase desired behavior in child. }\end{array}$ \\
\hline $\begin{array}{l}\text { Sixth } \\
\text { season }\end{array}$ & $\begin{array}{l}\text { Training elimination and reduction methods of inappropriate behavior which at this meeting is } \\
\text { about a-positive ways to decrease the behavior (1- divisive strengthening the behavior at low rates } \\
\text { and other behaviors 3- divisive strengthen of Inconsistent behavior 4- soak or saturation) }\end{array}$ \\
\hline $\begin{array}{l}\text { Seventh } \\
\text { season }\end{array}$ & $\begin{array}{l}\text { Teaching negative behavior reduction methods (1- silence 2- deprivation of Strengthening 3- } \\
\text { Penalizing 4- compensate 5-punishment) }\end{array}$ \\
\hline $\begin{array}{l}\text { Eighth } \\
\text { season }\end{array}$ & $\begin{array}{l}\text { Use of daily report cards and recommendations for parents(Use of daily report card of behavior in } \\
\text { school, a list of consequences of behavior, building the table of self-regulatory behavior (academic } \\
\text { and behavioral) and advices to parents about ways of appropriate Interaction with these types of } \\
\text { children in the fields of communication and education. }\end{array}$ \\
\hline
\end{tabular}

Children's cognitive- behavioral education also is done in this way that in the first meeting attended by parents expressed the purpose of the meetings and coordination of the timing and need for training exercises by children. 
These training sessions were also conducting at the same time with behavioral tests group and conducted as one session a week and 8 weeks totally. In these meetings the summary of mentioned discussion were recorded at the end of each session by the students and in some cases by educators in their notebook And the students were asked to do training exercises at home. Also at the beginning of each training session, summary of the last meeting expressed for students very briefly. Educational content expressed as follows:

Table 2.

\begin{tabular}{|c|c|}
\hline Sessions & ontent \\
\hline $\begin{array}{l}\text { First } \\
\text { season }\end{array}$ & $\begin{array}{l}\text { tudents familiarity with symptoms of this disorder in simple language and recommendations about } \\
\text { ontrol of sleeping conditions, food and ... }\end{array}$ \\
\hline $\begin{array}{l}\text { Second } \\
\text { season }\end{array}$ & $\begin{array}{l}\text { The student becomes familiar with the relationship between thoughts, feelings and behavior and } \\
\text { with fundamental and basic thoughts which can affect the other thoughts and feelings and behavior } \\
\text { (consistent with the theory of Ellis and Beck) }\end{array}$ \\
\hline $\begin{array}{l}\text { Third } \\
\text { season }\end{array}$ & $\begin{array}{l}\text { he student can identify his negative thoughts (become familiar with the concept of thought } \\
\text { acking) and acquainted with the most common thinking errors. }\end{array}$ \\
\hline $\begin{array}{l}\text { Forth } \\
\text { season }\end{array}$ & $\begin{array}{l}\text { The student can identify his negative thoughts (become familiar with the concept of tracking } \\
\text { thoughts) and became familiar with the most common thinking errors. The student will be familiar } \\
\text { with the concept of thought control, and became familiar with positive self-training concept and } \\
\text { concept of self-talking coping (According to Mayken Bom theory) }\end{array}$ \\
\hline $\begin{array}{l}\text { Fifth } \\
\text { season }\end{array}$ & $\begin{array}{l}\text { Imiliar with the concept of stress, } \\
\text { self) }\end{array}$ \\
\hline $\begin{array}{l}\text { Sixth } \\
\text { season }\end{array}$ & $\begin{array}{l}\text { Methods of controlling of emotions and regulation it with different situations (Student became } \\
\text { familiar with a concept of Muscle Relaxation and sport exercise, which causes reduction of } \\
\text { undesirable feelings and emotions and the importance of choosing the suitable words to convey his } \\
\text { thoughts and feelings in interpersonal relationships). }\end{array}$ \\
\hline $\begin{array}{l}\text { Seventh } \\
\text { season }\end{array}$ & $\begin{array}{l}\text { Learning problem-solving approach (the student will be familiar with this concept that, stand, think } \\
\text { before making any decision and then decide and examine all the pros and cons of any decision). }\end{array}$ \\
\hline $\begin{array}{l}\text { Eighth } \\
\text { season }\end{array}$ & $\begin{array}{l}\text { Academic skills training (students became acquainted with some study skills, self-monitoring and a } \\
\text { table of self-attributions). }\end{array}$ \\
\hline
\end{tabular}

In these meetings were recorded the summarized of what was said by the students and in some cases they by the educator in their notebook at the end of session and the students were asked to do training exercises at home. Also at the beginning of each training session, summary of the last meeting were expressed very briefly.

\section{Research Tools}

Connor's test of parents which contains short form is 27 questions that was completed by the mothers of subject. Subject's score in each question is between zero and three that the sum of subject's scores divided by the number of questions is (27).

Test cut-off point to diagnose this disorder is $5 / 1$. The age range used in the scale of Connors is between the ages of three to seventeen years. The final internal coefficients with amplitude range of $75 \%$ to $90 \%$ and final retest coefficients with the 8-week distance have been reported $60 \%$ to $90 \%$ (Zargari Nejad, 2007). This questionnaire has justifiability, formal and content (Shefaat and Tiregi, 2012).

\section{Diagnostic Checklist for Disorder of Attention Deficit/Hyperactivity}

This questionnaire has created according to the fourth edition of the Diagnostic and Statistical Manual of psychiatrists' America Association Mental Disorders and psychologists and psychiatrists have confirmed its justifiability, formal. In Iran reliability of this test has been reported 82\% (Khosravi and Alizadeh, 2010).

The children's Chesler and intelligence test conducted of second grade and Raven test conducted of third, fourth and fifth grade as a group And the experimental and control groups became homogeneous on the basis of educational grade, intelligence and the variances of dependent variable.

\section{Findings}

Data in two levels of descriptive statistics (Abundance, average) and inferential, Kolmogorov-Smirnov test for normality of the scores distribution, Levens test for equality of variances and covariance analysis were analyzed.

Demographic characteristics of subjects included 19 in the second grade, third grade 13 cases, 8 cases fourth 
grade, and fifth grade 7 cases. In these three groups were 12 girls and 35 boys. Their parents' degree of education was from primary school to Master of Science. The analytical results of the study were as follows too:

Behavioral parent training is effective in reducing symptoms of students with attention deficit / hyperactivity disorder (subgroups of mainly oblivious, impulsive, and combined).

Analysis of covariance was used, to test this hypothesis. In this way that at the first necessary default for the analysis of covariance (matching scores with the normal curve and uniformity the control group's score variance with the experimental group and in homogeneity hypothesis of regression slope in this variable) were examined.

Since there were the necessary conditions for the implementation of covariance analysis, this method was used to test this hypothesis. The descriptive comparison with controlling group averages by testing the dependent and covariate variables:

Table 3. Average and standard deviation of IQ variables, pretest and posttest of attention deficit / hyperactivity disorder symptoms with separation of group variable (evidenced by testing behavioral training)

\begin{tabular}{lcccc}
\hline Group & Indexes & IQ & $\begin{array}{c}\text { Pre-test of disorder } \\
\text { symptoms }\end{array}$ & $\begin{array}{c}\text { Post-test of disorder } \\
\text { symptoms }\end{array}$ \\
\hline Control & Mean & 96.47 & 11.2 & 10.67 \\
Experiment of & Standard deviation & 14.711 & 3.649 & 4.012 \\
behavioral education & Mean & 99.47 & 10.29 & 8.47 \\
\hline
\end{tabular}

Above table shows average and standard deviation of IQ variables, pretest and posttest of attention deficit / hyperactivity disorder symptoms with separation of group variable (evidenced by testing behavioral training of parents). Accordingly, In terms of descriptive it can be said average of subjects in these two groups do not differ substantially in the pre-test. But the difference between the two groups' averages in post-test is relatively impressive.

Table 4. Analysis of post-test scores covariance of attention deficit / hyperactivity disorder as a function of group variable with pre-test covariate scores of this variable and also IQ covariate scores

\begin{tabular}{lcccccc}
\hline Source & $\begin{array}{c}\text { Sum of } \\
\text { squares }\end{array}$ & $\begin{array}{c}\text { Degrees of } \\
\text { freedom }\end{array}$ & $\begin{array}{c}\text { Mean } \\
\text { squares }\end{array}$ & F & $\begin{array}{c}\text { Significant } \\
\text { level }\end{array}$ & $\begin{array}{c}\text { Effec } \\
\text { t } \\
\text { value }\end{array}$ \\
\hline Pre-test (covariate) & 275.31 & 1 & 275.31 & 114.9 & 0.000 & 0.804 \\
& & 1 & 13.15 & 8 & & \\
IQ (covariate) & 13.15 & 1 & 11.81 & 4.93 & 0.026 & 0.164 \\
$\begin{array}{l}\text { Group } \\
\text { (Control-test) }\end{array}$ & 11.81 & 28 & 2.39 & & & \\
Error & 67.04 & & & & & \\
\hline
\end{tabular}

Above table shows results of post-test scores covariance analyses of attention deficit variable disorder as a function of group variable with pre-test covariate scores of this variable and also IQ covariate scores.

As has come in this table, the significance level of covariate pre-test variable effect on dependent variable (post-test), IQ covariate variable effect on dependent variable (post-test), also the significance level of independent variable(group) effect on dependent variable (post-test) is less than 0.5 and it is significant.

This means that the IQ variable and scores of pre-test are effective on post-test scores and In this analysis, after removing IQ variables and pre-test effect, the influence of an experimental variable is significant yet and its effect is 15 percent.

This result indicates that in this analysis the covariance after removing the variable of significant group's effect is significant. This means that the control group subjects' post-test averages experiment in attention deficit variable have significant differences and actually the experimental conditions has been caused symptoms of attention deficit subjects' reduction.

So as a result we can say: the behavior parent training is effective in reducing symptoms of students with 
attention deficit / hyperactivity disorder (subgroups of mainly oblivious, impulsive, and combined).

Cognitive behavioral training is effective to reducing the symptoms of students with attention deficit / hyperactivity disorder (subgroups of mainly oblivious, impulsive, and combined mostly).

To test this hypothesis, due to the fact that there was a requirement condition for the implementation of covariance analyses this method was used to test this hypothesis.

The descriptive comparison of control groups' averages by experimenting in Covariate and dependent variables:

Table 5. Average and standard deviation of IQ variables, pretest and posttest of attention deficit / hyperactivity symptoms by separation of group variable (as evidenced by testing Cognitive-behavioral)

\begin{tabular}{llccc}
\hline Group & Indexes & IQ & $\begin{array}{c}\text { Pretest of } \\
\text { symptoms }\end{array}$ & $\begin{array}{c}\text { Posttest of } \\
\text { symptoms }\end{array}$ \\
\hline Control & Mean & 96.47 & 11.2 & 10.67 \\
& Standard deviation & 14.711 & 3.649 & 4.012 \\
Experiment of & Mean & 101.2 & 9.47 & 8.67 \\
behavioral education & Standard deviation & 12.763 & 3.777 & 4.047 \\
\hline
\end{tabular}

Above table shows average and standard deviation of IQ variables, pretest and posttest of attention deficit / hyperactivity symptoms by separation of group variable (as evidenced by testing Cognitive-behavioral)

Accordingly, it can be said in terms of descriptive, average subjects of these two groups didn't have significant difference in these three tests.

Table 6. Post-test scores covariance Analysis of attention deficit / hyperactivity disorders symptoms variable as a function of group variable by pre-test covariate scores of this variable and also the covariate IQ scores

\begin{tabular}{ccccccc}
\hline Source & $\begin{array}{c}\text { Sum of } \\
\text { squares }\end{array}$ & $\begin{array}{c}\text { Degrees of } \\
\text { freedom }\end{array}$ & $\begin{array}{c}\text { Mean } \\
\text { squares }\end{array}$ & F & $\begin{array}{c}\text { Significant } \\
\text { level }\end{array}$ & $\begin{array}{c}\text { Effect } \\
\text { value }\end{array}$ \\
\hline Pre-test (covariate) & 254.63 & 1 & 254.63 & 168.1 & 0.000 & 0.866 \\
& & & & 7 & & \\
IQ (covariate) & 12.59 & 1 & 12.59 & 8.32 & 0.008 & 0.242 \\
$\begin{array}{c}\text { Group } \\
\text { (Control-test) }\end{array}$ & 0.13 & 1 & 0.13 & 0.09 & 0.769 & 0.003 \\
Error & 39.37 & 26 & 1.51 & & & \\
\hline
\end{tabular}

Above table shows the results of post-test scores covariance Analysis of attention deficit / hyperactivity disorders symptoms variable as a function of group variable by pre-test covariate scores of this variable and also the covariate IQ scores.

As has come in this table significant level of pre-test covariant variable effect on dependent variable (post-test) is less than 0.5 and so is significant. The significant level of IQ covariate variable influence on the dependent variable (post-test) is less than 0.5 and so it is significant.

But significant level of independent variable (group) effect on the dependent variable (post-test) is more than 0.5 , and therefore it is not significant. This means that in this analysis, IQ and pre-test variables were effective on post-test scores an in this analysis after removing IQ and pre-test variables effect, cognitive-behavioral effects of experimental variables is not significant any more.

This result indicates that in this covariance analysis after removing the effect of covariate variables the influence of group's variable is not significant anymore.

This means that the pre-test averages of control group and experiment of attention deficit / hyperactivity symptoms variable doesn't have significant difference with each other and in the experimental conditions (Cognitive Behavior training of parents) has not caused the attention deficit symptoms reduction of subjects and its effect had been only $0.3 \%$. So as a result, we can say that: cognitive-behavioral parent training is not effective in reducing symptoms of students with attention deficit / hyperactivity disorders. 


\section{Discussion and Conclusion}

This research was evaluated to effects of parent's behavioral training program and behavioral-cognitive training on reducing the symptoms of attention deficit disorder/ hyperactivity and results showed the effects of parent's behavioral training program on reducing the symptoms of this disorder. This research is coordinate and favorable with Bahmani and Alizade (2011), Abedi and colleagues (2012), Narimani and colleagues (2014) and Khodabakhshi and colleagues (2015) researches and it isn't favorable with Page and colleagues (2003) and Alizade (2012) researches.

The result can be known due to difference of the subjects in terms of the demographic features of the subjects, in explaining this hypothesis .As Thorndike prominent American psychologist believes, the psychological variables can be changed for each organism or different organisms from time to time in various environmental conditions (Hooman, 1995). Also these differences can be due to training content and training method.

The most important point that is notable and it is suggested to be considered to that in all future research, is parents expectation level variable that it seems that their expectations have changed to these children by training of them and as a result, that will be effect on their attitude and adjudication about these children and finally, it will be effective in answering to test questions by parents however, this is a noteworthy point that is notable in all pencil-paper tests.

As the American Psychiatric Association (2013) believe that parent training can lead to improving parental interactions and this improvement can be due to adjusting their expectations levels .In other words, training subjects (parents) about a problem can change parents and these cognitive shifts can be effective in way of answering to test questions and in fact, the expectations levels of parents can be operated as a mediator variable between independent training variable and the dependent reducing the symptoms of attention deficit disorder/ hyperactivity variable.

Although the expectations levels and parents expectations can be confounded as the meddler variable in order to justifying and explaining the mental processes that they cannot be observed directly but explains the behavior In other words, the meddler variable is the mental variable that however it cannot be directly seen and felt but it can be deducted from the behavior of (subjects) for example the hostility variable is deductible from aggression variable.

On the other hand, the problem can be looked from this angle that cognitive shifts of parents about interactions with these children have affected on their way of answering with their children and this impact improves self-regulation mechanism in children than parents .In fact, cognitive shifts of parents lead to behavioral changes in them and its result is improving self-regulation mechanism of children with parents.

Because when parents instead of considering their children only being rebellious and disobedient children and compare them with others or their other children continuously and knows each other as a responsible for such behaviors of their children, try to precept the physical and mental condition of them and ignore some of their small negative behavior and take more responsible role in presenting parental patterns and performing the educating talent that is the suitable and right using from incentives and rebukes and having more coordination with each other in issuance of effective commands they will be effect on the way of answering and their behavior to their children and the result of this effeteness is improving acts and behavior of their children that this improvement of behavioral acts can be effect on mutually on behavioral stability of parents and be considered as a reinforcing agent for behavioral continuation of parents.

According to what said about performance of the pencil paper tests (including this research) in relation to children with attention deficit disorder / hyperactivity and tried to analyzing the problem from different perspectives. So it is suggested to all researchers, including counselors, psychiatrists and psychologists to use tests such as continuous performance test that are more objectively and it seems that the error variance is less. For example, quantitative EEG-based measurement of children with attention deficit / hyperactivity in pre-test and repeating measurement in times after the application of parents behavioral training variable can lead to better elucidate of this disorder from the perspective of the biological approach.

Of course it seems that according to heavy financial costs ((brain measurement waves)) it is better to enough accuracy is done in number of the subjects and it is better to match subjects in terms of the different variables of the Intelligence, degree and income of parents, education grade of student and other demographic variables to determine the amount of the effectiveness or non-effectiveness of parents behavioral training on reducing the symptoms of this disorder more objectively and the accuracy of comparing increases significantly between behavioral training and behavioral cognitive on reducing the symptoms of children with attention deficit / 
hyperactive throw this way.

Of course it should be considered that the generalizability of the results to other experimental situations and with different subjects, decreases by improving the internal validity of experimental groups and improving the comparison condition between two training methods also the consideration of this issue is important that observing the research provisions of external validity and conjugation substitute of children with attention deficit / hyperactivity in the experimental groups randomly cannot provide complete and necessary confidence to us about in other situations, but supplant of subjects randomly can increase the generalizability chance of the results.

Furthermore, the result of second hypothesis indicated that behavioral cognitive training is not effective on reducing the symptoms of attention deficit disorder / hyperactive .The obtained result is not favorable and coordinates with Meftaq and colleagues (2011), Hassan abadi and colleagues (2012), Luchman and colleagues (1981), Brawzvil and colleagues (1983), Queen and Astren (1388/1997) researches and it is coordinate and favorable with Soleimani and colleagues (2013), Safern and colleagues (2010 quoted from Atensil and colleagues, 2014), Vatder (1392 / 1995), Ramsi and Rastin (1390/2005) and Pelham and colleagues (1998) researches. In explaining the results of this hypothesis can be paraphrased that according to that the majority of subjects in groups and in cognitive behavioral group were in second and third grade of elementary schools and this group of children did not have necessary cognitive skills to understand and implementing the cognitive behavioral concepts so it was not observed tangible changes in their behavior in parents reporting.

Significant issue that was felt in training of this group was providing the training content to this subject group for training these children that included second to fifth grade was so difficult according to individual differences. Since training the behavioral cognitive group that they have low accuracy domain and don't have enough and tranquility during the grouped training, it is very strenuousness work.

Therefore, it is suggested that it is better to use personal method to training this group on the future. Another important point that was obtained the from the result of this research was according to the speech-based training method and even grouped discussions for these students that they are so different in terms of the cognitive is not true work. So it is suggested to other researches who are supposed to do cognitive behavioral training work due to the weakness of these children in selective attention, to use creative methods like using training games that are effective on the improvement of the cognitive concepts of these children or use animations that attractively include useful cognitive concepts for these children.

Another point that it seems trainers can use is matching the subjects of the experimental groups that is according to age, intelligence, economic-social base and educational base. Because it was observed, children who are in the fourth and fifth grades have more suitable preparation cognitively and mentally for these kinds of trainings. This point is repeated again according to the importance of the comparing the training methods.

Subject's assignment in terms of the mentioned variables can improve the internal validity condition of the research and make suitable field for increasing the amount of the effective accuracy of two behavioral cognitive methods of parents but the as the same proportion the external validity of research is reduced and generalizability power of results is reduced.

Another subject that it was seen in this group said that cognitive training of self-training skills and presenting the self-supervisory is more realizable for students with attention deficit / hyperactive in second and third grades, therefor it seems that for increasing the lull and attention level of these children it can be used drug and after that start to training the behavioral cognitive concepts, of self-training skills, self-supervisory, strategies of solving problem and self-strengthening (American Psychiatric Association, 2001; Pelham, weiler \& Crotis, 1991; quoted from Pich \& colleagues, 2003).

Another point is so important and it is suggested to another researches is to do the behavioral cognitive training in different time process. As the Barckly believes the mental-social treatments is better to do in different distances and periods and this program generally that on that training program encompass parents, family and teacher is done to behavioral cognitive training activities be more coordinate and more organized to become useful by this method for children with this disorder that they aren't answer to drugs and that are around the 20 to 30 percent.

Because according to their social and cognitive defects these trainings can help them up to they can be responsible for their personal and social responsibilities (Becake and colleagues, 2015). Quoted from martin (2005) different methods have their own benefits and defects and these benefits and defects should be told to parents to take decision by themselves. At last it can be said, as psychology science has tried to engage body, mind and brain (Seyyed Mohammadi, 2003). Attention deficit disorder/ hyperactivity are a neurological-growth 
disorder that must be work on interaction of these three components (body, mind and brain) constantly.

\section{References}

Abedi, S., Pourmohamadreza, M., Mohamadkhani, Parvaneh., \& Farzi, M. (2012). Effectiveness of positive parenting program on mother-child relationship in children with attention deficit disorder / hyperactivity. Journal of Clinical Psychology, 3, 73-63.

ADHD Parents Medication Guide American Academy of Child \& Adolescent Psychiatry and American Psychiatric Association (2013). ADHD Parents Medication Guide. Retrieved from http: //www.parentsmedguide.org/parentguide_english.pdf

Alizadeh, H. (2005). Theoretical explanation attention deficit / hyperactivity disorder: the pattern of behavioral inhibition and self-control nature. Research on Exceptional Children, 5(3), 348- 321.

Alizadeh, H. (2007). Attention deficit hyperactivity movement. Tehran: growth.

Alizadeh, H. (2012). Parental training programs for families with children with attention deficit / hyperactivity disorder and its impact on reducing symptoms and family functioning. Special Quarterly, 7, 70-43.

Alizadeh, H., Hossein, Al., Panah, A., Goudarzi, A. M., \& Zrfshan, H. (2013). Comparison of the draw, the ability to organize and visual memory - spatial children with and without attention deficit / hyperactivity. Journal Research Cognitive and Behavioral Sciences, 1(4), pp. 10-1.

American Psychiatric Association (2000). Diagnostic and StatisticalManual of Mental Disorders (4th Ed.). Washington, DC: Author.

American Psychiatric Association (2013). (Syed Y. \& Syed Mo, Trans., 1393). Tehran: Minister.

Amiri, M., Alizadeh, H., \& Farokhi, N. A. (2013). The effect of mother's education and the positive signs and negative approach -Draykvrs Adler Children with attention deficit / hyperactivity. Journal of Psychology exceptional, 12, pp. 25-1.

Antshel, K. M., Faraone, S. V., \& Gordon, M. (2014). Cognitive Behavioral Treatment Outcomes in Adolescent ADHD. Journal of Attention disorders, 18(6), 483-495.

Bahmani, T., \& Alizadeh, H. (2011). The effect of behavior management training to mothers to improve parenting practices and reduce symptoms of attention deficit / hyperactivity. Special Psychology, 1, 39-27.

Bakhshayesh, A. R. (2010). Diagnosis and treatment of attention deficit hyperactivity disorder, Yazd, Yazd University Press.

Barkley, R. A. (1998). Attention-deficit hyperactive disorder: A handbookfor diagnosis and treatment (2nd Ed.). New York: Guilford Press.

Behiyat, S. (2011). Attention Deficit Hyperactivity Disorder Treatment Review. Catalyst, 1(6), pp. 12-17.

Bikic, A., James, F. L., Lindschou, J., Torben, C., \& Torben, D. (2015). Cognitive computer training in children with attention deficit hyperactivity disorder (ADHD) versus no intervention: study protocol for a randomized controlled trial. Bio Med Central, 16(480), 1-13.

Blasco, F. H., Gonzalez, P. M., Garcia, L. R., Poza, C. B., Perez, M. M., De Leon, M. V., \& Jose, OteroMonitoring and Self-Monitoring. Journal of Family Research, 9(4), pp. 451-470.

Dr. Abdolkarim, M., Mousavi, v. A., Khosro, J., M., \& Kusha, M. (2011). Parent Management Training impact on marital satisfaction mothers of children with attention deficit / hyperactivity disorder. Journal of Guilan University of Medical Sciences, the course of the twentieth, 80, 84-74.

GheraghMolaii, L., Khosravi, Z., \& BaniJamali, S. (2014). The Role of Monitoring in Reducing Behavioral Problems in 6-12Years Old Girls with ADHD: A Comparison Between Maternal.

Hakim, M., Lavasanat, M., Shakuri, H. R., Abdollahi far, A., \& Moemeni, F. (2015). Compare the effect of behavioral therapy, pharmacotherapy and behavior therapy and medication combined reduction of symptoms of attention deficit / hyperactivity. Journal of Medical Science, 53, 47-42.

HasanAbadi, S., Mohammadi, M. R., \& Ahgar, G. (2012). The Comparison of Cognitive Behavioral Therapy (CBT) vs Drug Therapy Effect in Reducing Symptoms of Attention Deficit Hyperactivity Disorder (ADHD). Mejds, 1(2), pp. 19-30.

Hooman, H. A. (1995). Knowledge of scientific methods in behavioral sciences. Tehran: Parsa

Houck, G., Kendall, J., MillerL, A., Morrell, P., \& Wiebe, G. (2011). Self-Concept in Children and Adolescents 
with Attention Deficit Hyperactivity Disorder. JournalofPediatric Nursing, 26(3), pp. 239-247.

Kordestani, D. (2014). The effect of behavioral parent training on improving the mental health of mothers with attention deficit hyperactivity disorder children and decreasing their children's externalizing behavior. Journal of Behavioral Sciences, 8(3), pp. 279-286.

Kouchakzadeh, S., Namazi, A., \& Zarkesh, M. (2015). Symptoms of attention deficit disorder / hyperactivity disorder in children under school age based on parent report. Journal of Nursing and Midwifery, 25(75), 45-35.

Kowsary, L., \& Alizadeh, H. (2010). A comparative study on social skills in primary students with and without Attention deficit Hyperactivity Disorder, 6(3), pp, 109-134.

Malekpour, F., Conductor, S., Cross-border, S., Love, R., \& Farmer, A. (1393). Compare the effectiveness of interventions in family-centered, child-centered and a combination of the symptoms of attention deficit / hyperactivity. Journal of Family Counseling and Psychotherapy, 150, pp. 673-653.

Martin, M., Cunnane, J. B., Gammon, D., Gang, J., Kirsch, D. R., Lendroth, H. P., ... Riccio, K. R. (2005). Attention Deficit HyperactivityDisorder (ADHD). Connecticut ADHD Task Force (3rd Ed.)

Mftaq, D., Mohammadi, N., Ghanizadeh, A., Merciful, G., \& Najim, A. (2011). Comparing the effectiveness of different treatment methods on attention deficit / hyperactivity children. Isfahan Medical School, 29(147), pp. 976-965.

Mishra, J., Sagar, R., Joseph, A., Gazzaley, A., \& Merzenich, M. (2016). Training sensory signal-to-noise resolution in children with ADHD in a global mental health setting. Transl Psychiatry, 45, pp. 1-9. Retrieved from www.nature.com/tp

Narimani, M., Shahly, A., \& Abbas, A. (2014). Parent Management Training impact on behavioral problems in children with Attention Deficit Disorder / Hyperactivity psychological Faly. Fslnamh New Research, 36, 135-142.

Navidian, A., \& Mosalanejad, L. (2015). Effectiveness of Positive parenting program for mothers of children with attention deficit / hyperactivity disorder on children's externalizing problems. Journal of Mental Health, 17(3), 137-143.

Paige, R., Pasternack, H. R., Lee, S., \& Danielson, C. L., (2003). Identifying and Treating Attention Deficit Hyperactivity Disorder: A Resource for School and Home. Department of Education Contract No.HS97017002 with the American Institutes for Research.

Parand, A. (2013). Education of children with attention deficit / hyperactivity disorder: strategies and challenges. Journal of exceptional education, 114, pp. 41- 38.

Pelham, W. E., Wheeler, T., \& Chronis, A. (1998) .Empirically supported psychosocial treatments for attention deficit hyperactivity disorder. Journal of Clinical Child Psychology, 27, 190-205.

Perez (2015). Efficacy of chess training for the treatment of ADHD: A prospective, open label study. Psiquiatr Salud Ment, 9(1), 13-21.

Ptacek, R., Stefano, B. G., Weissenberger, S., Akotia, D., Raboch, J., Hana, P., ... Goetz, M. (2016). Attention deficit hyperactivity disorder and disordered eating behaviors: links, risks, and challenges faced. Neuropsychiatric Disease and Treatment, 12, pp. 571-579. Retrieved from https://dx.doi.org/10.2147/NDT.S68763

Russell, R. J., \& Genuine, A. E. (2008). Hyperactivity disorder in adults Cognitive behavior therapy movement. (A. Mashhadi, Azam and Ismail Sultani decree. Trans., 1390). Tehran: The Sound of the propagated light.

Sarraf, N., Yousefi, K., Majlesi, F., \& Noori, K. (2015). Determining effectiveness of multimodal parent management training combined with methylphenidate on academic achievement, oppositional and behavioral symptoms of school aged children with attention deficit hyperactivity disorder. Razi Journal of Medical Sciences, 22(138), pp. 32-44.

Seid Mohammadi, Yahya. (2003). Reading in Pschology.Tehran: RavanPublication.

Shefat, A., \& Tirigi, A. B. (2012). Prevalence of depression in mothers of children with attention deficit hyperactivity disorder. Journal of Mazandaran University of MedicalSciences2012, 21(1), 66-71.

Skogli, E. W., Teicher, H. M., Andersen, P. N., \& Hovik, K. T. (2013). ADHD in girls and boys - gender differences in co-existing symptoms and executive function measures. BMC Psychiatry, 13(298), pp.1-12. 
SmithF, T., Schmidt, -K. R., McGeary, E. J., Jessica, A. K., \& Knopik, S. V. (2016). Pre- and Perinatal Ischemia-Hypoxia. The Ischemia-Hypoxia Response Pathway, and ADHD Risk, 46(3), pp. 467-477

Soleimani, M., Motie, S., Yaghubi, H., \& Hazrati, L. (2013). The effectiveness of cognitive training program on cognitive skills and symptoms of attention deficit / hyperactivity in children. Journal of Disability Studies, 3(3), 49-39.

Stallard, P. (2005). Cognitive-behavioral drman. (H. Alizadeh, A. Mental \& A. M. Goudarzi Trans., 2010). Tehran: Danzhh.

Vander, P. H. (1995). Attention deficit disorder / hyperactivity disorder in adults. (D. S. Foroushani Trans., 1387) Tehran: growth.

Vysany, M., Aalipour, M., Mehrabi, M. (2015). The effect of parent-child communication method of training the inadequate attention disorder / hyperactivity. Journal of Family Psychology, 2(1), pp. 29-38.

Zarei, S., Sharif, F., Shoushtari, A. A., \& Vosughi, M. (2014). The effect of stress management training on the mental health of mothers of children with attention deficit / hyperactivity. 3(4), 67-58.

Zargarinejad, G. (2007). Efficacy of parent's training on problem behaviors in ADHD children. Psychological Studies, 3(2), pp. 29-48.

\section{Copyrights}

Copyright for this article is retained by the author(s), with first publication rights granted to the journal.

This is an open-access article distributed under the terms and conditions of the Creative Commons Attribution license (http://creativecommons.org/licenses/by/4.0/). 